\title{
Brazilian health care faces harsh choices
}

$\mathrm{T}$ he assessment was blunt and the options stark. Brazil's health care system needs reorganization and faces a distinct choice.

"The future of Primary Care in Brazil is either a model similar to the United States, with upper and middle classes having private insurances and the low classes having something like welfare, or a model like Canada, with universal coverage, a public system and strong Primary Care," Dr. Juan Gérvas, a member of a Spanish team funded by the Brazilian government to assess the state of the country's primary health care system, writes in an email. "The future will be promising if the political decision helps making Primary Care a filter for Specialist Care, if it potentiates Family Medicine and if health centres are provided with enough resources."

The assessment, conducted by the not-for-profit research firm Team CESCA on behalf of the Brazilian Society of Family and Community Medicine, found a number of flaws in the Brazilian government's plan — the "Family Health Strategy — to reorganize primary health care (Editor's note: final report is available in Portuguese at www.sbmfc .org.br/media/file/Visita_Espanhois_2011 /SBMFC_relatorio\%20final.pdf).

Those included:

- inadequate and fragmented acute, primary and home visiting services

- insufficient numbers of qualified family doctors
- poor coordination between levels of care

- ineffective teamwork

- absence of a policy to compel physicians to constrain their labours to one facility, rather than to work multiple shifts at various facilities

- lack of scientific and technological development

- excessive focus on prevention instead of treatment

- excessive referrals to specialists and emergency departments

- "overuse" of resources, such as conducting unnecessary tests, prescribing unnecessary antibiotics for urinary infections, persistent use of nebulizers and the use of fetal dopplers during low-risk pregnancy consultations

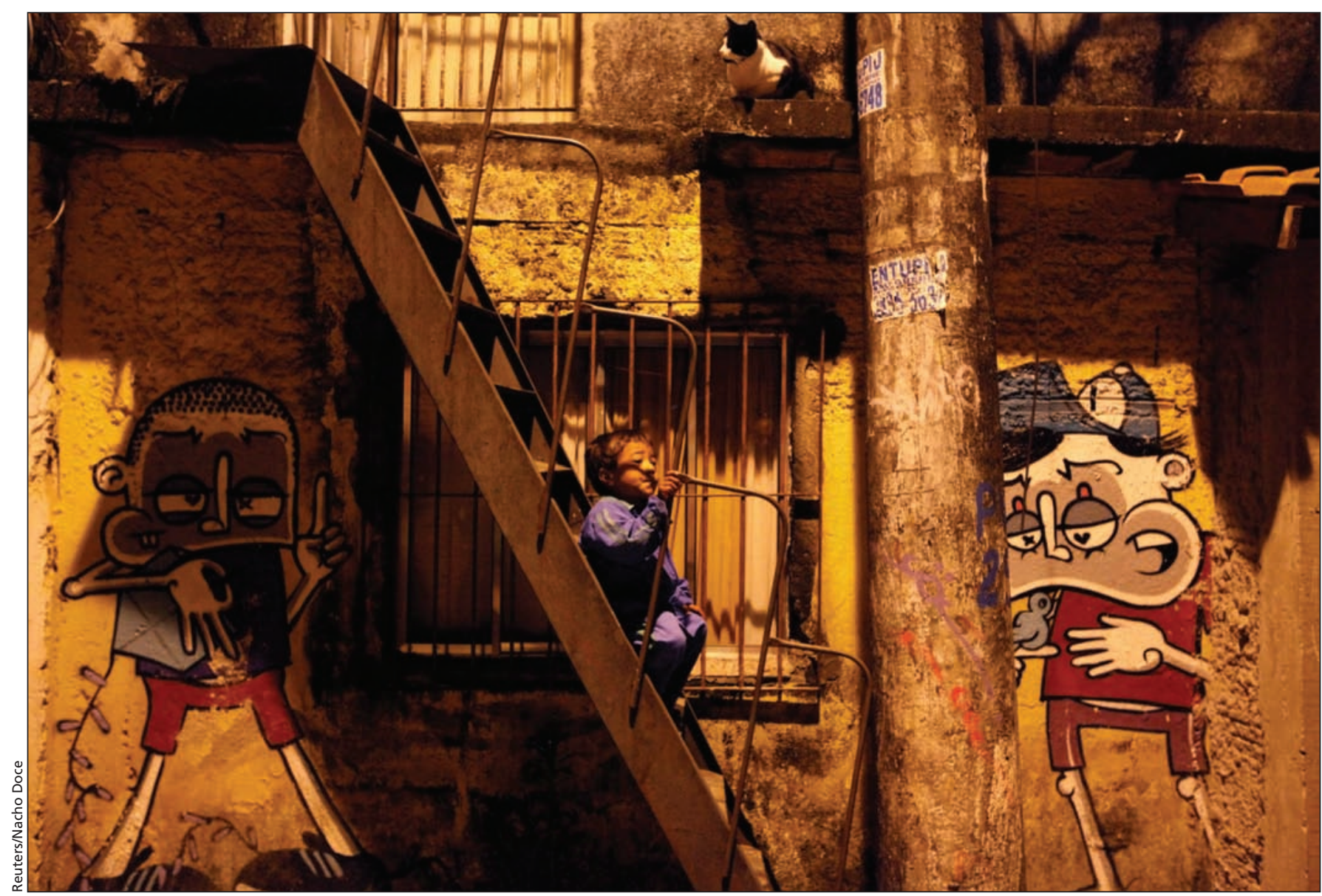

A child sits on the stairs of a house next to graffiti painted by Brazilian artist Chivitiz, a member of OPNI, (a Portuguese acronym meaning "Unidentified Graffiti Artists"), which was formed in 1997 to improve conditions in the Vila Flavia favela (shantytown) of Sao Paulo. 
- unattractive pay and incentives for health professionals.

Somewhat surprising was the criticism that the Brazilian system focuses too heavily on preventive measures, given that in most nations, the converse is true.

But it's a definite problem in Brazil, Dr. Daniel Knupp, a family physician and head of the residency program of the Brazilian Society of Family and Community Medicine, writes in an email. "The excessive focus on health promotion and prevention removes credibility from the Family Health Strategy before the population, managers and doctors, particularly future doctors, who don't feel enticed to work in a primary care system maintaining that focus. Breaking that logic is a key aspect for the Family Health Strategy to flourish."

The Brazilian government has committed itself to significantly expanding primary care services for the country's population. The system now covers about $75 \%$ of the population through services provided at 60000 health centres. In about one third of those, care is provided by a multidisciplinary family health care team, which is typically comprised of a family doctor, a nurse, a nursing assistant and community health agents, and typically funded by contributions from the federal, state and municipal governments.

Critics have charged that Rio de Janeiro, in particular, has been slow to expand health services within its slums but defenders of the system have argued that it's a highly problematic task to build the health infrastructure and hire the health workers needed to provide primary and dental care for the more than one million people living in the city's often violent hillside slums, while also improving care for its remaining 11.6 million residents (www.cmaj.ca /lookup/doi/10.1503/cmaj.109-3700).

The expansion of services into slum areas was one of the positive developments within the Brazilian system identified by the Spanish team. Others included the existence of pharmacy and dental medicine services within health centres; the independence of clinicians from the influence of the pharmaceutical industry; the use of complementary and alternative medicines; and expanding use of telemedicine.

Gérvas and Dr. Mercedes Pérez Fernandez, who undertook an extensive tour of Brazil, concluded in their report that Brazil requires profound reform of its primary care services and structures in order to make it "strong, resolvent, accessible, well endowed with technology, with polyvalent professionals capable to respond to $90 \%$ of the population needs."

They also argued that family doctors need to have more authority to coordinate health services and determine which patients see specialists.

In terms of professional development, the consultants concluded that Brazil needs to: make residency training mandatory; improve its continuing medical education programs; fund more doctors through capitation; promote more house calls; and provide more incentives for doctors to work in remote and rural areas.

Knupp, though, says efforts are already being made to improve the training of family doctors, including one program to promote distance learning and another to expand residency positions.

Others say that the review exercise has already yielded dividends, namely, the triggering of "a profound process of reflection," as Dr. Gustavo Gusso, head of the Brazilian Society of Family and Community Medicine, writes in an email. - Tiago Villanueva MD, Lisbon, Portugal

CMAJ 2011. DOI:10.1503/cmaj.109-3996 